
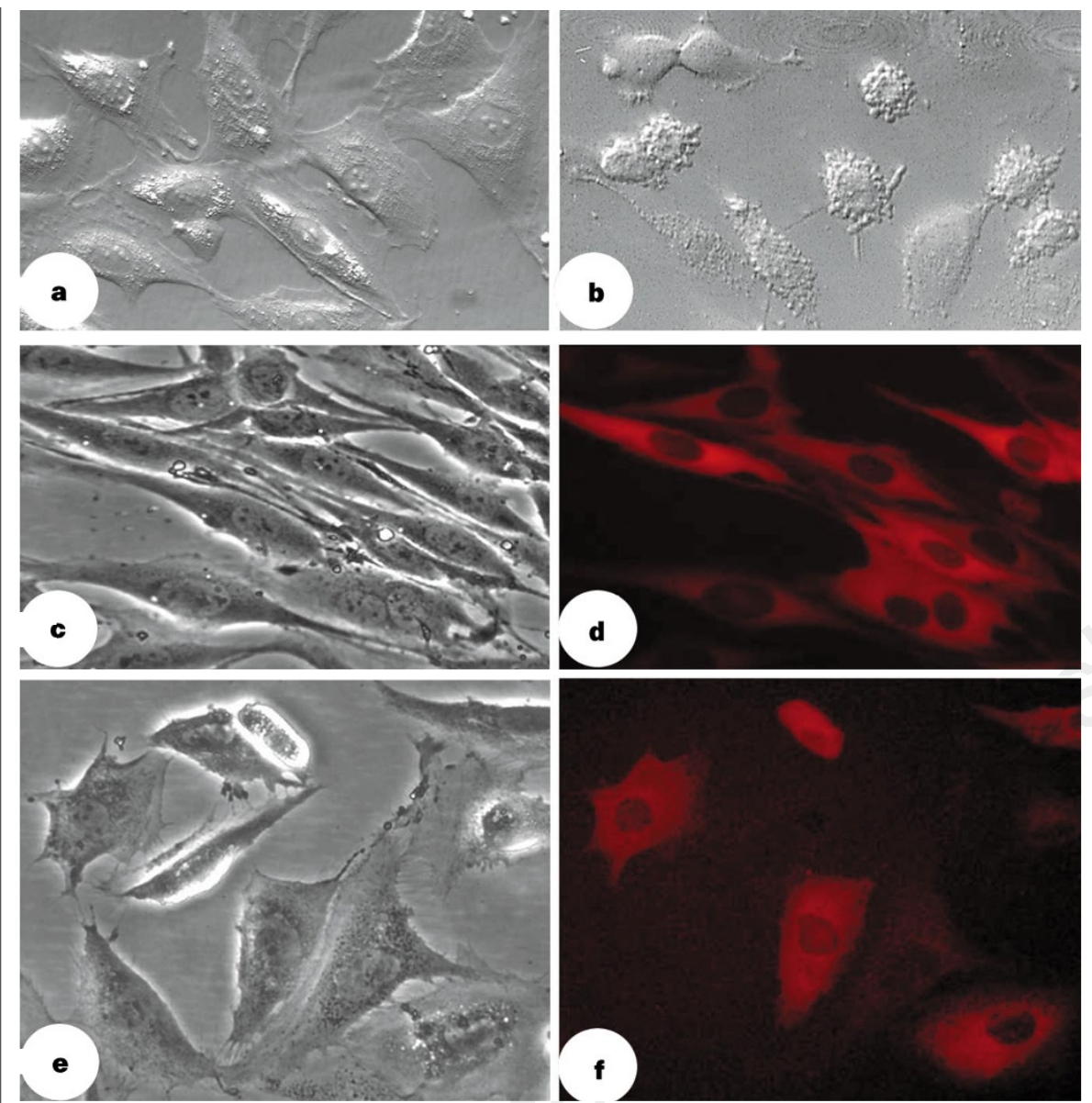

Figure 2 Morphology of microinjected NRK cells. a, Control cells. b, Wild-type cells injected with $20 \mu \mathrm{M}$ cytochrome c. c, Wild type cells preincubated with Z-VAD-fmk for 30 min and co-injected with $20 \mu \mathrm{M}$ cytochrome $c$ and $0.1 \mu \mathrm{g} \mu \mathrm{l}^{-1}$ TRITC. d, Fluorescence micrograph of the same field as that in (c). e, Cells overexpressing Bcl-2 co-injected with $20 \mu \mathrm{M}$ cytochrome $c$ and $0.1 \mu \mathrm{g} \mu \mathrm{l}^{-1}$ TRTC. f, Fluorescence micrograph of the same field as that in (e).

and Bcl-2 overexpression, respectively (Fig. 2d, f).

Our results indicate that injected cytochrome $c$ can induce apoptosis in various cell types, and that this effect is caspasedependent. It has been suggested that the role of $\mathrm{Bcl}-2$ protection is restricted to its mitochondrial location, where it prevents leakage of cytochrome $c^{5,6}$. Microinjection of cytochrome $c$ bypasses the need for release of this protein from mitochondria. However, cells overexpressing Bcl-2 were also protected from the apoptosis induced by injecting cytochrome $c$. This could be explained in several ways.

First, Bcl-2 is not restricted exclusively to the mitochondrial membrane, hence some of its anti-apoptotic property might be based outside this location ${ }^{1}$. Second, Bcl-2 may be a member of the 'apoptosome' complex and it could prevent cell death by direct binding to Apaf-1/Apaf-2/Apaf-3, in a similar way to CED-9's activity on CED-3/CED-4 proteins 9 . Third, it has been reported that cytochrome $c$ binds to $\mathrm{Bcl}-\mathrm{X}_{\mathrm{L}}$ (Ref. 10). Bcl-2 may exert a similar quenching effect outside mitochondria. Fourth, Bcl-2 targets several proteins, including overexpressed, Bcl-2 could possibly act as a transporter for cytochrome $c$ back into mitochondria ${ }^{12}$.

Boris Zhivotovsky, Sten Orrenius

Institute of Environmental Medicine,

Division of Toxicology, Karolinska Institute,

S-171 77 Stockholm, Sweden

e-mail: Sten.Orrenius@imm.ki.se

Odd T. Brustugun, Stein O. Døskeland

Department of Anatomy and Cell Biology,

University of Bergen, Arstadveien 19, N-5009

Bergen, Norway

1. Hockenbery, D., Nunez, G., Milliman, C., Schreiber, R. D. \&

Korsmeyer, S. J. Nature 348, 334-336 (1990).

2. Tsujimoto, Y. Cell Death Differ. 4, 429-434 (1997)

3. Kroemer, G. Cell Death Differ. 4, 443-456 (1997).

4. Liu, X., Kim, C. N., Yang, J., Jemmerson, R. \& Wang, W. Cell 86, 147-157 (1996).

Yang, J., et al. Science 275, 1129-1132 (1997).

6. Kluck, R. M., Bossy-Wetzel, E., Green, D.R. \& Newmeyer, D. D. Science 275, 1132-1136 (1997).

Mellgren, G., Vintermyr, O., Bøe, R. \& Døskeland, S. Exp. Cell Res. 205, 293-301 (1993).

8. Hampton, M.D., Zhivotovsky, B., Slater, A. F. G., Burgess, D. H. \& Orrenius, S. Biochem. J. 329, 95-99 (1998).

9. Hengartner, M. O. Nature 388, 714-715 (1997).

10. Kharbanda, S., et al. Proc. Natl. Acad. Sci. USA 94, 6939-6942. (1997)

11.Wang, H.-G., Rapp, U. R. \& Reed, J. C. Cell 87, 629-638 (1996) 12. Scaife, J. F. Canad. J. Biochem. 44, 433-448 (1966).
Raf-1, to mitochondria ${ }^{11}$. Therefore when

\section{Tumour regression after endostatin therapy}

It was with great interest that we read the report ${ }^{1}$ on the lack of acquired drug resistance to repeated doses of endostatin in experimental cancers in mice. Of particular interest is the unprecedented finding that each tumour type became indefinitely dormant after a varying number of treatment cycles. We believe one explanation for this phenomenon might be found in the clinical observation that, after complete regression of large bulky tumours, rebiopsy of the primary tumour site will frequently show large amounts of fibrosis or scarring.

Pharmacological doses of endostatin, a C-terminal fragment of collagen XVIII with relative molecular mass 20,000 , at very low concentrations may be deposited in the extracellular matrix with each cycle of therapy, analogous to amyloid deposits in patients with light-chain disease. The marked shrinkage of the mouse tumours from approximately $250-450 \mathrm{~mm}^{3}$ to $5-50$ $\mathrm{mm}^{3}$ could effectively increase the local extracellular matrix concentration of endostatin 5-50 fold. Each successive cycle of regrowth followed by treatment and regression could progressively increase the concentration of endostatin in the local extracellular matrix until the concentration is sufficient to inhibit further angiogenesis.

This phenomenon of preferential concentration could explain the observation of a dormant primary tumour while the same tumour type inoculated at a distant site would be uninhibited. The extracellular matrix concentration of endostatin at these distant sites could be several log factors below the concentration at the primary tumour site and insufficient to inhibit tumour-driven angiogenesis.

If this hypothesis is correct, it could mean Boehm et al. have serendipitously discovered the ideal way to administer endostatin therapy, delivering a high inhibitory concentration of endostatin at the primary tumour site while keeping the systemic extracellular matrix concentration below the level necessary to inhibit naturally occurring angiogenesis such as wound healing. An assay of the relative concentration of endostatin at the primary tumour site compared to distant tissue concentration should establish if this is the basis for the observed phenomenon.

William R. Black

\section{R. Christopher Agner}

Departments of Internal Medicine

and Medical Oncology,

Rowan Regional Medical Center,

Salisbury, North Carolina 28144, USA

1. Boehm, T. et al. Nature 390, 404-407 (1997). 